\title{
RELATIONAL, ROLE, AND SOCIAL IDENTITY AS EXPRESSED IN GRANDPARENTS' PERSONAL WEB SITES
}

\section{JAKE HARWOOD}

This paper reports on an investigation of personal web sites created by grandparents. The paper examines the sites and uncovers important themes relating to the grandparent-grandchild relationship, the grandparenting role, and age identity. References to age are relatively rare, occurring largely in siles created by younger grandparents, and siles concerned with social activism. A number of way's in which being a grandparent is represented as a meaningful social identity are described. Conclusions are drawn in terms of theoretical links between relational, role, and social identities and issues of importance to the relationship between grandparents and grandchildren. It is argued that a social identity theory perspective provides interesting insight on the examination of communication about family relationships.

\section{KEY WORDS: Grandparent, Grandchild, Internet, Family, Communication.}

A s we seek to understand the nature of human relationships, it is important to examine communication within and about those relationships in a variety of contexts. Such examinations can enhance our understanding of the relationships themselves, and can increase our knowledge of the relational partners-how they understand the relationship and how it relates to other aspects of their lives. The current study examines one way in which grandparents communicate about their relationships with their grandchildren-grandparents' personal websites. The research aims to enhance our understanding of the grandparent-grandchild (GP-GC) relationship and the ways in which communication about this relationship relates to a grandparent's more general conception of his/her own self.

Increasingly, scholars are recognizing the ways in which identity is contextually determined or constructed through discourse. Research has described the ways in which age identities are expressed and constructed in intergenerational conversations (e.g., N. Coupland, Coupland, \& Giles, 1989) and the ways in which age identities are manipulated in medical encounters (J. Coupland, Robinson, \& Coupland, 1994). Similarly, Hecht and colleagues' model of cultural identity recognizes its essentially malleable nature (Hecht, 1993) and hence the importance of examining discursive constructions of identity. Such work intersects with research adopting a discourse analytic perspective on social psychology (e.g., Billig, 1996; Potter \& Wetherell, 1987). From this perspective, understanding the ways in which identity functions requires understanding how it is represented in everyday discourse. Hence, examining themes of identity in discourse is essential to our understanding of people's self-concepts and relationships.

The current research focuses particularly on on-line communication. The growth of the Internet as a communication medium is well recognized and its relevance as a site for self-expression is growing. It is used for multiple forms of self-presentation such as artistic expression, autobiographical narrative, self-disclosure on illness, and posting curriculum vitae. Increasingly, the Internet is being used for collective purposes-hate groups are spreading their messages via the WWW (Leets, 2001), political groups are

Jake Harwood (PhD, University of California, Santa Barbara, 1994) is an Associate Professor at the University of Arizona. Thanks to Andrea Lambert and Ashley Spaulding ( $O$ 'Neal) for their assistance in coding and data collection and Mei-Chen Lin for her comments on an earlier version of the manuscript. Comments of anonymous reviewers and Jim Query are also greatly apprecialed. Preparation of this manuscript was made possible by support from the University of Kansas General Research Fund. 
seeking members through on-line expression (Holmes, 1997), and cultural groups are using the Internet to join together (Mitra, 1997). Hence, interest is growing in the ways in which identities are expressed on-line (e.g., Baym, 1999; Lin, Hummert, \& Harwood, in press; Mitra, 1997; Turkle, 1995; Wynn \& Katz, 1997). As the Internet becomes accessible to diverse populations, such work provides a new avenue to understand identity. Web pages are a context in which individuals present themselves in monologue for an extended period of time. Generally we only obtain this sort of self-description in autobiographies or research questionnaires. The former tend to only be produced by "famous" people, while the latter are solicited. The Web's naturally occurring discourse allows the examination of individuals' unprompted, conscious and deliberate constructions of their identities. Such written texts may reveal a somewhat different take on the social constructionist approach to identity. While identities may fluctuate and be negotiated "on the fly" in interpersonal interaction, when individuals set down who they are in writing for a public context, they might take particular care to present themselves in ways that are acceptable to the self across multiple audiences and over time.

In the current research, personal web pages created by grandparents were examined to understand more about the GP-GC relationship and how identity as a grandparent interacts with identity as an older adult. The introduction to the paper reviews relevant work on the GP-GC relationship and examines the concept of identity as it might relate to these websites. It is worth noting that, despite stereotypes of technological incompetence among older adults (Ryan, Szechtman, \& Bodkin, 1992), older adults are the fastest growing group of Internet users (Seniornet, 1998) and the Internet is facing a "silver tsunami" as the baby boomers approach retirement age (Fox et al., 2001). Hence, increased attention to the ways in which older people are using the on-line environment is particularly important right now (White et al., 1999). Fox et al. suggest that one of older adults' primary motivations in going on-line is the maintenance of personal relationships-particularly those with children and grandchildren.

\section{The Grandparent-Grandchild Relationship}

The number of older adults in the population is growing due to aging baby boomers and increasing longevity (Annan, 1999; Rowe \& Kahn, 1998). As a result, the GP-GC relationship is lasting longer than ever before (Szinovacz, 1998; Uhlenberg, 1996). The vast majority of adults over the age of 65 are grandparents (Roberto \& Stroes, 1992). Data indicate that these are very important relationships (Brussoni \& Boon, 1998); perhaps second in importance only to parent-child relationships (Kornhaber, 1985). For the grandchild, the GP-GC relationship is a context in which they may have frequent and intimate contact with an older adult, something that is rare outside of this relationship (Brussoni \& Boon, 1998; $\mathrm{Ng}$, Liu, Weatherall, \& Loong, 1997). As a result, experiences within the GP-GC relationship may influence younger adults' attitudes towards older adults (Harwood, Hewstone, Paolini, \& Voci, 2003; Silverstein \& Parrott, 1997). For grandchildren, the relationship can also be a place in which confidences are shared and family histories are learned, in an environment perceived as more "free" than in conversations with parents (Harwood, McKee, \& Lin, 2000); Nussbaum \& Bettini, 1994). For grandparents, research suggests that the relationship may influence their levels of psychological well-being (Cai, Giles, \& Noels, 1998 ) and even "keep them young" (Harwood et al., 2000). Harwood and Lin (2000) examined relational themes in grandparents' descriptions of interactions with their grandchildren. These authors suggested that affiliation (expressions of love and mutual 
caring), pride in the grandchild, exchange (e.g., of knowledge, resources), and distance are central in grandparents' accounts of the GP-GC relationship. The distance theme concerned geographical/psychological distance and constituted the most significant negative aspect of the relationship. Even when grandparents loved and took pride in their grandchildren, they were disappointed by infrequent contact and opportunities for close interaction.

Harwood (2000) found that a substantial amount of GP-GC communication occurs through channels other than face-to-face and telephone communication-presumably some of this was occurring through the Internet. Recent work has suggested that computer-mediated communication may be growing in importance and frequency for older adults (Seniornet, 1998; Wright, 2(100). Given these facts, the examination of the ways in which the GP-GC relationship may be operating on-line seems useful. The perspective of the current paper is that the study of the GP-GC relationship from a communication perspective involves not just communication in the relationship, but also communication about the relationship. How we communicate about important relationships is important in shaping our own perceptions of the partner and the relationship as well as our partners' perceptions (Berger \& Bradac, 1982); Duck, 1992). Hence, in examining grandparents' communication about their grandchildren on personal web sites, a first research goal of the current study was to examine relational themes-how is the relationship characterized, and what elements are important to the grandparents. We believed that salient themes in the webpages might reveal important factors in grandparents' relational identities pertaining to their grandchildren.

RQ1: What are important themes in grandparents' webpage accounts of GP-GC relationships?

\section{Grandparenting, Aging, and Social Identity}

This study's primary theoretical interest in the GP-GC relationship stems from identity issues. We define identity as an individual's conception of the nature of the self. Tajfel and Turner's (1986) social identity theory (SIT) divides identity into two areas. Personal identity is a person's conception of their own individual characteristic's such as their traits, likes and dislikes. Social identity is a person's conception of the groups to which they belong, along with evaluative connotations attached to those group memberships. Tajfel and Turner suggest that social identity can influence self-concept. If groups with which we identify are negatively valued, those memberships will negatively influence our self-concept, and vice versa. When social identity is negative, SIT suggests ways in which individuals can act to obtain more positive social identity, including disassociating from the group (social mobility), changing the basis for intergroup comparisons (social creativity), or actively challenging the status quo (social competition) (Tajfel \& Turner, 1986). From a SIT perspective, being a grandparent can be seen as part of personal identity: It is an individual characteristic, shaped by the particular family experience. Grandparents are not traditionally perceived as a meaningful social group. However, two issues complicate this perception: (a) The relationship between the grandparenting identity and age identity, and (b) the ways in which the grandparent identity itself may actually constitute a social identity.

First, many grandparents share an important social identity, their age identity (Harwood, Giles, \& Ryan, 1995). Many grandparents are older adults and many will identify with other older people in terms of their living situation, their political affiliations, or their shared history (Garstka, Branscombe, \& Hummert, 2001). We know little about whether identifying as a grandparent is associated with identifying as an older person, although J. Coupland, Coupland, Giles, and Henwood (1991) discuss 
the ways in which disclosing grandparenthood as a role status may serve as a means of disclosing age. The transition to grandparenthood raises age issues because the normative, stereotypic image of a grandparent is that of an older adult, despite the fact that the transition can occur as early as around 30 (Burton \& Bengtson, 198.5). Hence, the transition is likely to precipitate age-related comparisons and self-reconceptualizations relative to the grandparent archetype or stereotype. These reevaluations of self may lead to age references in public accounts of the role. Examining the ways in which grandparent and age identities intersect gains particular currency when we consider that older adults are not highly regarded in society (Kite \& Johnson, 1988). In contrast, grandparenting is generally a valued role in society, and representations of grandparenting are largely positive (Mavrogenes, $1982 ; \mathrm{Ng}$ et al., 1997)-indeed Hummert, Garstka, Shaner, and Strahm (1994) use the label "perfect grandparent" for one of their positive age stereotypes. In other words, the grandparent role and identity may imbue an aging identity with positive features (Harwood \& Lin, 2000)-a form of "social creativity" (Tajfel \& Turner, 1986). Put differently, if we are to understand more about grandparenting, a SIT perspective argues that it is essential to examine the relationship in the context of relevant social group memberships, and particularly social group memberships that are associated with social stigma (e.g., old age).

However, grandparents are an extremely diverse group in terms of their ageboth in everyday life and in our data. As elaborated later, many of them are considerably younger than our traditional boundaries for being "elderly" $(6.5+)$. That raises interesting social identity issues; Some grandparents may feel the need to disassociate themselves from any perceived identification with older adults. A form of "social mobility" (Tajfel \& Turner, 1986) may come into play as grandparents discuss their (relatively young) age as a way of distancing themselves from the traditional image of the grandparent. Again, we will come to a greater understanding of this through examining the ways in which age is talked about in the context of the grandparent role.

A second issue related to social identity involves grandparents joining together to address concerns specific to them as a group. Recent cases before the Supreme Court have addressed issues of grandparents' visitation rights with grandchildren over the objections of the child's parents (Troxell v. Granville, 2000; see Holladay \& Coombs, 2001). Organizations are forming to address the shared interests and concerns of grandparents (e.g., The Foundation for Grandparenting). Additionally, increasing numbers of pages dedicated to grandparenting are appearing on the WWW and crucially they are being joined into webrings. Webrings are collections of personal websites that are connected based on their particular theme. Any individual with a personal website may choose to associate their site with one or more webrings. This enables any visitor to their site to connect with other related sites by a single click, or to connect with a directory of all sites on the ring. Thousands of webrings exist for all manner of diverse interests and experiences, from individuals with a shared hobby to those with unusual medical conditions. The fact that grandparents are creating webpages on the grandparenting experience and joining them together into webrings demonstrates that (a) the experience of being a grandparent is sufficiently important that individuals feel the need to express that identity publicly, and (b) these individuals are interested in joining together to express this identity as a group.

Given this discussion, a second research goal of the current study is to examine the ways in which grandparents describe and express their role in an on-line environment, and the ways in which they may express identification with others based on either their age or their role. Both age and role can be understood as collective or social (Tajfel \& 
Turner, 1986) identities. Links between age identity and grandparenting identity are reinforced as organizations such as the AARP provide support and develop initiatives surrounding grandparenting (see www.aarp.org). The examination of such links advances work in SIT, in that it considers the ways in which a particular identity (being a grandparent) may transcend personal, relational, role, and social identities. Public expressions related to grandparenting seem likely to include descriptions of the grandparents' place in the relationship itself (relational identities: RQ1), their orientation to the role of grandparenting (role identity), their identifications with other grandparents (a social identity), and their identifications with their age group (also a social identity).

RQ2: In what ways do grandparents' role and social identities interact in their webpage accounts of relationships with their grandchildren?

\section{METHOD}

Given the absence of background literature on grandparent identity, a primarily qualitative approach was adopted to examine the research questions. The research examines personal web sites devoted to grandparenting for common themes related to the grandparenting relationship, the grandparent role, and aging. From the outset it was recognized that themes related to these categories would overlap.

\section{Sample}

Personal web sites produced by grandparents were examined. Identification of such sites was achieved by examining a grandparenting webring (www.webring.com) that included 334 such sites at the time of data collection (see earlier description of webrings). Personal grandparent sites outside of the webring are difficult to locate and achieving a representative sample of such sites is impossible. Therefore, the study focuses on a random selection of sites from the ring. Use of random samples is somewhat unusual in qualitative work, however it serves the purpose of providing a manageable data set and one that we can say with confidence represents the diversity of the sites as a group. We set out to do the first round of analysis on 10 sites $(12 \%$ of those on the ring)-from our preliminary examination this number appeared to provide enough variety while keeping the volume of data manageable. Generating this sample of 40 required an initial random sample of 61 sites ( $18 \%$ of those on the ring), from which three sites not in English and 18 sites containing no information about grandchildren or grandparenting were deleted. The analysis revealed considerable com. monality in the content of these 40 sites; a larger sample appeared unnecessary (Potter \& Wetherell, 1987).

Six sites $(15 \%)$ were dedicated grandparent sites containing only information concerning grandchildren, family members related to the grandchildren, and being a grandparent. The remaining 34 sites contained information about other topics (e.g., the grandparents' work or hobbies). In other words, the majority of the sites examined were general personal web sites with a section that focused on the grandchild. The name(s) of grandchildren were mentioned in 31 sites $(77 \%)$, their ages were mentioned in $20(50 \%)$, and photos of grandchildren were provided in 25 sites $(62 \%)$. Information such as whether the site was constructed by a grandmother or grandfather was available sporadically. No sites explicitly described step-relationships, adopted grandchildren or other non-traditional GP-GC relationships, but it is possible that some of the relationships were of these types. 
Analysis

All text relevant to grandparenting was copied into the qualitative analysis software $N 5$ (QSR, 2000). Sections not relevant to grandparenting were excluded. The text was divided into sentences, and sentences were treated as the unit of analysis ( $N=$ 581 ; approximately 47 pages of text). The text was examined in detail, focusing on themes of the GP-GC relationship, descriptions of grandparenting and grandchildren, family issues, and aging in general. The important categories emerged from the texts through detailed reading (described below). The broad plan for analysis was derived from methods set out by Potter and Wetherell (1987), Silverman (2001), and Strauss and Corbin (1998).

A three-stage process of analysis was used. First, five complete passes were made through the data, during which statements that might be relevant to theme development were noted. The focus here was on discourse relating to grandparenting and grandchildren, family issues, and aging in general. Two complete passes to develop preliminary themes for coding supplemented these passes. The themes were coded in N5. Hence, the initial development of themes was an entirely interpretive process. Second, once the preliminary categories were established and coded, text searches were performed in $\mathrm{N} 5$ to find other text units related to specific themes (e.g., the "affiliation" theme was examined via a search for words like love, affection, and closeness-sentences including those words were examined for their relevance to the theme). The text searches were not used for automatic coding, but rather as an additional aid to identify exemplars that might have been missed with the manual coding. The text searches also helped bring up exemplars on the boundaries of themes, resulting in additional clarification. Through an iterative process involving manual textual analysis with automated assistance and numerous additional passes through the data (Potter \& Wetherell, 1987), the themes were elaborated, refined, or in some cases collapsed or deleted. This process followed a broadly constant comparative approach (Silverman, 2001) whereby the data and the emerging themes were constantly being compared and the themes adjusted in relation to the data. Third, we generated lists of (a) all sentences coded into each category, and (b) all sentences not coded into each category. Both sets of reports were examined separately to validate the inclusion and exclusion of sentences in themes (a form of deviant case analysis: Silverman, 2001).

This was a qualitative and interpretive process involving attention to context. In order to understand a particular sentence's meaning the immediate textual context was considered (e.g., to understand the referent for a pronoun), as well as the context of the relationship (e.g., to understand whether a relationship was maternal or paternal) and other features (e.g., web conventions to understand the use of emoticons, examination of photographs and graphical elements on the page to understand particular references in the text; these were accessed by going back to the original website-textual data were linked to the URLs). One advantage of using $N 5$ is that it permits coding specific sentences in a text while the surrounding text is still available to provide context.

Reliability and validity of this coding process was achieved in a number of ways (Silverman, 2001). First, the texts were examined on numerous occasions over many months: The total number of passes through the entire data set was not tracked but it is estimated that all items were read at least twenty times in the course of category development, coding, and refinement. This repeated exposure resulted in assignments to categories and themes with which the researcher feels comfortable and which have stood the test of repeated reexaminations of the data. Second, the examinations of the 
TABLE 1

Frequfncies of Coding; Categories Rflative to Total Ni mber of Text Units and W'eb Sites EXAMINED

\begin{tabular}{llc}
\hline \hline & $\begin{array}{c}\text { Text units } \\
N(\%)\end{array}$ & $\begin{array}{c}\text { Web sites } \\
N(\%)\end{array}$ \\
\hline Relational themes & & - \\
Affiliation & $68(12.0)$ & $27(68.0)$ \\
Pride & $30(5.2)$ & $14(35.0)$ \\
Exchange & $33(5.7)$ & $11(28.0)$ \\
Distance & $13(2.2)$ & $6(15.0)$ \\
Role themes & $20(3.4)$ & $5(12.0)$ \\
Grandchild's perspective & $28(1.8)$ & $14(35.0)$ \\
Naming & $14(2.4)$ & $8(20.0)$ \\
Role identification & $15(2.6)$ & $7(18.0)$ \\
Social identification & $14(2.4)$ & $6(15.0)$ \\
Age themes & \\
\hline
\end{tabular}

Note. The first column reports the number of text units representing a particular theme, and the percentage relative to the total number of text units in the database $(N=581)$. The second column reports the number of websites containing at least one text unit representing a particular theme, and the percentage relative to the total number of websites examined $(N=40)$.

data occurred using various techniques (see above). The use of different techniques for approaching the data enhances the validity of the final outcome (Strauss \& Corbin, 1998). Third, numerous examples of each theme are provided in the text, therefore the coherence and clarity of the categories is available for the reader to judge. Finally, where relevant, examples that are at the edges of categories' limits are provided below. These "borderline" exemplars are included to illustrate where a category's boundaries become fuzzy (which is necessarily the case with many categories of socially-produced materials).

\section{RESULTS}

This section is divided into three parts: Relational themes (RQ1), grandparent role themes ( $R Q 2$ ), and age themes (also $R Q 2)$. The themes are listed in Table 1 , along with their frequency of occurrence in the data. Quantitative data can be useful in a qualitative analysis for providing a broad overview of the data to complement the specific qualitative examples (Silverman, 2001). In the table, the frequency of occurrence of each theme is presented as a proportion of the total number of sentences and the total number of sites. As Table 1 shows, the categories in the current analysis accounted for a relatively small percentage of the total number of sentences in the data. This should not be over-interpreted: The web pages contained a large amount of "filler"-important to the coherence of the site but not meaningful for our analysis (e.g., "Hello!", "Megan."-a photo caption, "I love Tigger.", "Thanks for coming!"). It is notable that the percentage of sites containing a particular category is consistently higher than the percentage of sentences-these categories are represented across multiple sites even though they represent a small percentage of the total discourse. The themes are not mutually exclusive. The issues examined here intersect in interesting ways and hence it was assumed that any sentence might incorporate elements of multiple themes. In all cases, extracts are referenced by the webpage number and the sentence number within that extract (e.g., 18:3 is the third sentence of web page 18). Identifying information has been changed. 


\section{Relational Themes}

Items reflecting the four themes described by Harwood and Lin (2000) (affiliation, pride, exchange, and distance) emerged repeatedly in the data analysis, hence that thematic organization was used.

Affiliation. This theme consists of all expressions of love, liking, relational solidarity, and connection between the grandparent and grandchild. A majority of the web pages examined included such affiliative references $(68 \%$ : see Table 1$)$ and in many cases the statements comprised a large portion of the site. For example, site 20 contained 12 text units, six of which were coded into this theme.

Descriptions in this category included the use of generic, generally metaphoric, positive adjectives such as wonderful, incredible, sweet, or terrific to describe the grandchild(ren) ("Two wonderful grandchildren" 15:2, "two terrific grandchildren" 48:4). In eight pages $(20 \%)$, this followed a pattern of giving the number of grandchildren, followed by a generic positive adjective and then the word "grandchild(ren)," although other uses of positive adjectives occur (e.g., "I'm a grandmom of a sweet two year old girl, Jolene" 53:2). Other features coded under this category include explicit expressions of love from grandparent to grandchild ("I love you just the way you are" 62:33) and the grandparents' perception of its reciprocation ("They love me so much" 64:20). The latter statements that the other loves self are evidence of a more profound and confident affection than a statement of feeling love for the other. Rhetorically, they may serve as a reinforcement or reminder for the grandchildren, who are a potential (and perhaps intended) audience for the sites. Also included in this theme were explicit statements of enjoying the grandchild's company ("My favorite thing to do is spend time with my husband, children, and grandchildren" 27:8; "I love spending time with him when possible" 33:42), and more generally taking pleasure in the grandchild's existence (e.g., as part of a longer poem about the sequential arrival of grandchildren, "Then the fourth came, what a great delight, and our love soared to an even greater height" 22:15). The use of a poem is telling here, given that genre's association with profound emotions and experiences. Affiliation is also expressed by descriptions of how children have "given" grandchildren to the grandparents ("Our oldest daughter has given us a beautiful grandson named Robert" 58:2). Equating the grandchild with a gift implies that they are valuable and "treasured" items.

Finally in this area, the data yielded statements concerning similarities in appearance or behavior across the generations that make the biological connection explicit ("Johnny looks just like his Mommy did at his age, but has many of his Daddy's mannerisms" 33:39; from the perspective of the grandchild "Now you know where I get my good looks!!" 26:12). These statements are put in the affiliation category because they emphasize the connection between the generations. For grandparents, these statements may reflect a role as custodians of family traditions and knowledge. Perceiving and commenting on the continuity of the family is a way to build and reinforce the sense of family as a meaningful entity. Interestingly, none of the sites mention any generations older than the grandparent. It would be possible to express family continuity through, for instance, the grandparent referring to his/her own grandparents. The fact that this does not occur may be a symptom of the grandchild-focus of the sites: References to older generations might be seen to distance the grandchild from people who s/he possibly never knew. There may also be control issues here. Commenting on older generations might threaten (or make salient the transitory nature of) the grandparent's role as family elder. 
One borderline example is included here to demonstrate the limits of the category. One page described the experience of seeing the grandchild's image on a sonogram ("To be able to peek into your creation is quite unbelievable. There are certainly no words that can fully describe that experience" 16:11-12). Such a statement does not include explicit statements of love or affection, however it does express a sense of great emotion at merely "seeing" the grandchild, hence it was coded into the affiliation category.

Pride. Many sites included units that were coded into the "pride" theme $(N=14$, $35 \%)$. Any references that appeared to reflect the grandparent's pride in their grandchild were included here. The most obvious were uses of the word pride and its derivations ("I'm proud of all 6 of them now" $62: 25$; "I am very proud of all my grandchildren" 21:4; "We have 5 grandchildren and are very proud of all of them" 22:2; "Who Is The Pride And Joy Of My Life" 26:5). Pride in grandchildren was also revealed by noting positive talk about grandchildren to others which reveals the public behaviors associated with pride (e.g., "Bragging about my grandchildren is easy" 16:3; "Can't wait to tell everyone" 33:46).

The remainder of the sentences in this category were positive descriptions of the grandchild that appeared to be literal ("Peggy ... is so cuddly and affectionate" $33: 27$; "Well, a perfect healthy and pink little girl, with black hair and big blue eyes has finally arrived" 39:4). Other such descriptions appeared as accounts of the grandchild's accomplishments or abilities "He can hold a conversation with you like an adult" 31:22). Academic accomplishments were a particular focus on one page that described the grandchild as being on the honor roll, having a perfect attendance record, and reading at a high level $(64: 26-29)$. There is clearly overlap between these comments and the generic positive adjectives in the affliation category. Determination of which category was more appropriate was made on a case-by-case basis. If the adjective was a specific description of a positive characteristic of the child (e.g., the child is apparently seen to be literally beautiful), then the comment was coded as "pride". If the comment appeared to be a general expression of positive affect (as with "incredible" or "wonderful") then it was coded as "affiliation". Where both seemed plausible, the unit was recorded into both categories.

Exchange. The exchange theme included all statements that described the grandparent or grandchild gaining something from the relationship. In order to keep this theme distinct from the "affiliation" category, simply giving or receiving love, affection, or caring were not included here. Shared enjoyment in an activity and exchange of knowledge or resources were included. This was a relatively common theme in the data, occurring in $28 \%$ of the sites. Grandparents tended to report exchange in the form of teaching and learning, as illustrated by the following example.

I have learned a lot from my grandchildren. I got very good at playing Nintendo ... ${ }^{*} S^{*}$. And I learned the names of the Teenage Mutant Turtles and Power Rangers and so many other "fun" things. " $\mathrm{S}$ " . I I did teach a couple of the grandchildren about computers (22:5-9)

This theme also emerged when the grandparent described providing the grandchild with material resources ("The boys like to come over to Grandma's because there's lots of toys, a big yard to run in, dogs to romp with, a room of their own to sleep in" 40:7). Grandparents also reported that they had made the web page for the grandchild, a gift of sorts. These comments were often made in sections of the pages that were written from the grandchild's perspective ("My Gramma made this page for 
ME!" 15:6; "This page was made by my Granny \& Grandpa!" 23:12). As in the first example above (22:5-9), the specific "rewards" that each party receives from the relationship are often presented together. Other pages are more general in the description of exchange, but still present the idea that both parties are benefiting (e.g., "The main thing is to have fun with the children you have been blessed with in your life, and enjoy the important role you have in theirs!" 20:7). The idea that grandchildren provide fun for the grandparents is emphasized even more explicitly in cases where the grandchildren are described as a hobby ("Our Interests \& Hobbies are our Grandkids" 19:2). This theme of exchange has theoretical relevance, particularly when considered in the context of suggestions that intergenerational exchanges in families are often perceived substantially differently from different perspectives (Harwood, 2001).

Distance. Grandparents reflected on how often they saw their grandchildren, bemoaned a lack of contact, or commented more generally on the nature of such contact. At times, these comments came in sections of the pages written from the perspective of the grandchild, in which the grandchild commented on missing the grandparents, or mentioned how much the grandparents would miss them (e.g., "My gramma \& grandpa, ... \& grandpa P will miss us a lot!” 15:30). At times, distance is geographical, as in an example where grandchildren have moved with parents to another country, or the following: "Max has recently moved away, but I love spending time with him when possible and he loves spending time with his Nana (and his other grandparents) $)^{n}$ (33:42). In other examples, the grandparents note high levels of contact in spite of some distance ("They are living with their Mom but we get to see them often since their Dad, my son, is living back at home" 40:6). In one instance, the specter of distance is raised as something the grandparent is glad to have avoided, suggesting that distance is a salient issue for grandparents, even when they do not suffer from it-perhaps because it is a theme of their discussions with other grandparents ("We have been fortunate to live close to our grandchildren and get to see them often" $22: 10$ ). Issues of distance are somewhat less frequent than the earlier themes (see Table 1).

The theme of distance in these data is less differentiated than that in the Harwood and Lin (2000) study. That study uncovered some negative descriptions involving feelings of psychological distance, a generation gap, or a GP-GC personality conflict. The current study only revealed a theme of infrequent contact or geographical distance. It is unlikely that grandparents would make web-pages for relationships that they felt were unrewarding, whereas noting such distance in an anonymous questionnaire (Harwood \& Lin's methodology) is more probable. In addition, Harwood and Lin examined older grandchildren's grandparents, and such relationships may have greater scope for alienation. Age of grandchild was not reported in all the pages under consideration here, but the majority appeared to be under 15 years old.

\section{Role Themes}

This portion of the analysis focused on concerns of self-as-grandparent. In large part, this issue was examined by looking at the ways in which terms for "grandparent" were used in the text. Eighteen relevant terms were uncovered in the text (grandmother, grandfather, grandpa, grandma, gramma, grampa, grandparent, granny, grandmom, pap, memère, nana, pop pop, paw paw, grampy, pappaw, mammaw, mommo). Diversity in family relational terminology is perhaps not unexpected; 
however, it may be a further indication of the importance of this relationship, given that complex lexical structures are likely to emerge for important constructs (Gumperz \& Levinson, 1996). These grandparent terms were used in $60 \%$ of the websites examined $(24 / 40)$ and were used in a total of 7.5 sentences (1.3\% of all sentences in all sites). Analysis indicated that these terms occurred in four contexts.

Grandchild's perspective. Grandparent terms were used to refer to the grandparent in sections that were written (by the grandparent) from the grandchild's perspective. These uses sometimes related to the way in which the website had been constructed ("My granny will update this page when I have my one year old birthday party" 64:60), but also touched on deeper relational issues. For example, in one example the grandparent wrote in the grandchild's voice about the grandchild's birth (“My: Pappaw, Mammaw, Mommo, Grampy, Granny, and others were in the waiting room, waiting on me to make my appearance" 64:46). Another page discussed the grandchild's family moving away from the grandparents ("My gramma \& grandpa, ...\& grandpa $\mathrm{P}$ will miss us a lot!" 15:30). Writing from the grandchild's perspective offers the grandparent the opportunity to refer to self by family role title, something that is not so easily accomplished in first person writing (interestingly, use of one's own role title when talking in the first person is a feature of baby talk and may be evaluated as patronizing: Hummert \& Ryan, 2001). At times, taking on the grandchild's persona also offers the opportunity to express affiliation and the reciprocation of that affiliation ("We love cookies and Sesame Street!!! (and of course, our Nana!)" 33:28-29).

Naming. Grandparent role terms were used by the grandparent in place of, or addition to, their name ("I am Gramma Nancy and I am glad you stopped by" 20:3). At times, these uses are in the initial sentence of the web page and serve to set a (homey) context for the page ("Grandpa's Porch" 31:1; "Hello, you have arrived at Nana's Attic." 41:2). At other times, these terms were used in place of first person pronouns (e.g., in a photo caption: "Grandma \& Kylie" 42:2; "The boys like to come over to Grandma's because there's lots of toys ..." 40:7). In other words, even when writing in first person, the grandparents used their role title in place of their name or a pronoun. As noted above, there are also hints of a baby talk style here, which may suggest that the audience for these pages is the grandchild(ren). However, it is also likely that the use of role title reflects role pride, a suggestion discussed further below.

Role identification. Grandparents also referred to themselves using the role-term preceded by an article (e.g., emphases added, "I knew I would enjoy being a Gramma, but I never in my wildest dreams knew how much!!" 20:11; "I'm a mother of 6 great kids and $a$ grandmother of 10 wonderful grandchildren" 48:3). This use is different from that described above. Specifically, in the current context, this use allows for an inference that there are other grandparents out there, and hence that this is a role that other individuals share. The article places the role of grandparenting at a more collective level than the use without the article. Hence, it is described here as role identification. In some cases, the article is used as grandparents describe how they may have been unprepared or unwilling to fill the role, or that the role did not "fit" them very well ("I was too young to be a grandmother, I didn't want to be a grandmother" $62: 5$; "The thing about me that surprises most people is that I am a grandmother" 27:5). There may be interesting links here to other contexts in which identities are taken on in a rather reluctant fashion (Hajek \& Giles, 2002). Other examples display 
more willingness to identify with the role, verging on an explicit solidarity with other grandparents ("Number one, I'm a grampa-that comes first" 16:2; 20:11 above).

Social identification. Grandparent terms are used to describe grandparents in general, express solidarity or identification with other grandparents, and in discussion of grandparenting-related issues. One comment is semi-humorous ("I would like you to see all my special angels that I have right now (everyone who is a grandparent knows this is subject to change)" 21:2-3), while another simply expresses an awareness of and shared identity with other grandparents ("But I am finding out now days there is all of us Nana's out there" $41: 13$ ). On a more political level, a few of the sites explicitly advocated collective action by and on behalf of grandparents as a group (e.g., "MY INSPIRATION To change the current laws here in New Jersey so that I and other grandparents can see and visit with our grandchildren!" 62:31; "The main focus of this site is strengthening the bond that exists between grandparents and their grandchildren-whether they live close by or too far away." 20:6). While these occurrences are rare, they indicate that some grandparents have a sense of identification and solidarity with others in their role. This identification leads them to discuss causes towards which they can work together-social competition in SIT terms. Interestingly, one of the pages concerning grandparents' rights also commented on negative stereotyping of grandparents that draws heavily on more general negative stereotypes of older adults:

Certainly, the images that come forth when someone describes a woman as "grandmotherly" are all too clear. Gray hair and knitting in a rocking chair come to mind, and a certain complex societal demotion takes place; grandmothers are thought to lack worldliness and sex appeal, to have lost their snap and creativity, to no longer be major players. But isn't it the stereotyping about grandmas that's really passé? $(62: 9-12)$

This extract is one of the few places in which group-based issues surrounding age and grandparenting appear to intersect and it is in the context of a social-activist message. This message suggests that social (age) and relational identity may coincide for grandparents when they face fights for legal status and authority. Perhaps it is normally difficult to make connections between a family role that is associated with non-intrusiveness or caring and a social identification with a broader group that carries with it some connotations of social action. Those connections may become apparent, and hence discursively salient, when social action is necessary in connection with the family role. A couple of other (subtle) references to stereotyping emerge in the text. In one case, the grandparent appears to support and reinforce a stereotype about grandparents ("As we all know Nana's have a lot in their attics" 41:3), while another appears to reject a stereotype ("Who said Memères (Grandmas) can 't dress up for Halloween?" $31: 41)$. The use of the plural is revealing here as an indication of treating grandparents as a social category.

This analysis indicates that terms related to grandparenting are used frequently and worked into these texts in various fashions. The frequency of use may reflect a sense of pride in the role of grandparenting (distinct from pride in the grandchild described earlier), suggesting that the role is an important part of grandparents' self-images. It may also reflect a sense of the intended audience for these pages. Perhaps, while writing, the grandparents were considering their grandchildren as an audience and referred to themselves using the term most familiar to their grandchildren. However, many features of the sites indicate that this was not the sole audience (e.g., the fact that the sites were linked into a webring implies awareness of a broader 
audience). In most cases, the grandparents are using the terms to refer to themselves, however the cases in which they are invoking the notion of a grandparenting collective are interesting in terms of the issues of identity and intergroup behavior outlined in the introduction.

\section{Age Themes}

It is clear from the literature (Burton \& Bengtson, 1985) and some of these web sites that one need not be "elderly" to be a grandparent. Nevertheless, as outlined by J. Coupland et al. (1991), the role references to grandparenting described above could all be seen as age references. Because being a grandparent is an age-associated role, any grandparent reference automatically invokes themes of age. For the purposes of this analysis, however, the ubiquitous references to grandparenting were separated from other age references. Tangentially, we should note that ages of grandchildren were frequently mentioned, both explicitly $(50 \%$ of sites, e.g., "Our new grandson ... Declan, 4 years old" 25:14) and implicitly (e.g., in descriptions of the relative age of two grandchildren: see 25:14 above). The ages of the grandparents' children were also occasionally mentioned ("I ... have two grown boys, one is 27 years old and the other is 25 years old" 18:1). However, our interest was specifically in the grandparent's age.

There was relatively little attention to the grandparents' age or aging in the data. Only 14 references to the grandparent's age emerged, in only six of the pages coded $(15 \%)$. Half of these were in the context of an off-time transition to grandparenthood ("I am 36 years old ... The thing about me that surprises most people is that I am a grandmother ... " 27:1,4; "I was in my 30's when I became a grandmother" 22:4). It seems that grandparents feel obliged to mark age explicitly when the grandparent transition is unusually early. These were the only disclosures of chronological age ( $\mathbf{N}$. Coupland et al., 1989).

The other references to grandparents' age were fairly subtle. In one page the grandparent commented that “... (a)t this point in my life I thought I had probably experienced pretty much every emotion there was..." (20:12). The "at this point in my life" is clearly a reference to advanced age. In a second case, a great-grandmother made a reference to the date of her daughter's birth, which offered a clue to her own age (". . . it was as if I was back in 1956 again holding her Grandmother, in my arms" $39: 7)$. J. Coupland et al. (1991) refer to this is a temporal framing process, which is a way of marking one's own age through reference to time past. One site offered a poem that used letters (G-R-A, etc.) to spell out characteristics associated with grandmothers. This site was unusual in talking about the general experience of grandparenting as opposed to the specific experience of that grandparent, and age references were present in the poem (" $\mathrm{A}$ - is for the agelessness she has ... D- is for the decades of experience she shares, M- is for the memories" 55:3-7). Below we discuss the issue of "agelessness" in more detail. Finally, another site also offered commentary on the grandparent role and made references to negative associations of aging (see quote from 62:9-12 above). Overall, the references to age in these data were rare and generally subtle. They became more explicit only when the transition to grandparenthood was off-time.

\section{DISCUSSION}

The analysis laid out important themes from these grandparenting web pages. This discussion examines some specific findings and draws implications for the study of grandparenting and identity, focusing particularly on (a) relational issues, and (b) social identity issues. 


\section{Grandparent-Grandchild Relational Issues (RQ1)}

The emergence of the four relational themes (affiliation, pride, exchange, distance) in the current data was not specifically hypothesized, but was useful given their previous presence in the literature (Harwood \& Lin, 2000). These themes would not necessarily translate to the study of other relationships, but they do provide a useful schema with which to understand grandparenting. For many grandparents, the relationship presents a complex emotional mix of love and pride on the one hand, and distance on the other. The repeated occurrence of the distance theme across quite different data sets, and the fact that it reveals otherwise rare negative commentary on this relationship is worthy of further examination. It is possible that such comments might engender considerable guilt in the middle-generation (or the grandchildren themselves once they are older), and they may be designed to achieve such an effect.

The frequency of the "affiliation" theme in these data may suggest that affiliation is a key element in social representations of the GP-GC relationship. This may be important in a few ways. First, this theme links nicely with data indicating highly positive communication experiences within this relationship (e.g., $\mathrm{Ng}$ et al., 1997). However, we should attend to the ways in which the dominance of the affiliation association actually may bias reports of communication in a positive direction. Second, the power of the affiliation theme may also have some negative effects, for instance for those who feel that their relationships do not match up to this ideal (e.g., as in the "distance" category). Third, there are some interesting links between this category and the "perfect grandparent" stereotype of older adults as described by Hummert et al. (1994). Specifically, the traits of warmth, caring, and love that Hummert et al. identified are the same ones that characterize this focus on grandparenting. This may simply mean that Hummert et al. selected an appropriate label for their stereotype. However, there may be deeper significance in terms of the origins of older adult stereotypes. As we seek to understand the cognitive organization of our knowledge and beliefs about human aging, we should heed the ways in which social representations of grandparenting feed into that organization. It seems possible that Hummert's "perfect grandparent ${ }^{n}$ stereotype is a vision of older adults that is derived from a more general representation of an idealized grandparent role. Such a finding would have important consequences in terms of understanding the development of ageism, and perceived variation within the aging population (Soliz \& Harwood, 2003). More detailed cognitive development of subcategories of older adults should be associated with increased perceptions of variability in older adults as a group, and a reduced tendency to negatively stereotype in a specific intergenerational situation (Richards \& Hewstone, 2001).

The data revealed interesting connections between some of the relational themes and more general family concerns. In particular, a number of sites made explicit links along lineage lines (e.g., explicitly noting which of the grandchild's parents was the grandparent's child), or noted similarities between grandparents or parents and grandchildren (e.g., in physical appearance). Such comments emphasize the role of a shared lineage in building shared identity within families. Likewise, the extent and diversity of family relationship references in the web pages was remarkable. Family members were often described by their relationships to one another, for example when the middle-generation was referred to as the grandchildren's parents or the grandparents' children, rather than using their name or a pronoun. Likewise, the grandparents referred to themselves as grandma or grandpa rather than using the first person. They 
also referred to their spouses in terms of their relationship to the grandchildren. The grandchildren were generally described as grandchildren, but they were also sometimes mentioned as the children of the children. Hence, interconnections within the family were made very explicit in these pages. We would argue that the pages serve to document the family and also to build familial interdependence and identity. In explicating the family relationships and referring to family members by their family role, the sense of connectedness and shared membership is reinforced.

An interesting related phenomenon is the number of sites featuring sections "ghost-written" by the grandchildren- $12.5 \%$ of the pages featured a section in the grandchild's voice that was clearly written by the grandparent. Again, these sections discussed family relations. That is, the grandparents would talk from the grandchild's perspective about the grandchild's siblings, parents and grandparents using family relationship terms. In all of these ways, we see the web sites as serving crucial functions in building family solidarity and family identity. Indeed, grandparents may see this as a central function that they serve-providing the next generations with the information about family relationships and the investment in the family structure necessary to preserve it. While not the primary focus of the current study, adopting such a role might be examined from a more critical perspective. There are ways in which taking the responsibility for documenting the family in a public context like the web and providing descriptions of the grandchild and the GP-GC relationship might be seen as serving political/social control functions. Specifically, the grandparent could be seen as using these sites as a means of framing the family and their relationship to the grandchild in their own terms, rather than having it framed by others (Langellier \& Peterson, 1993). Interview work with the grandparents might help tease out such possibilities.

\section{Age Identity and Social Identity Issues (RQ2)}

The relative lack of explicit age reference in the text was somewhat surprising. As described previously in the literature, age disclosure is a common theme in the conversational discourse of older adults ( $\mathbf{N}$. Coupland et al., 1989). In the context of a web page, the interpersonal exigencies that might precipitate age disclosure may simply not be present. For instance, Coupland et al. describe how age disclosure may serve an accounting function when the older person is explaining a decrement. In these sites, they have the choice not to raise any issues of decrement, and hence accounting is not necessary. Also, the sites may be a setting in which grandparents assume that their audience knows their age, either because (a) they created the page purely for their family members to view (although this is unlikely given the webring link), or (b) because they assume that everyone is working from the shared assumption that grandparents are old-a thought reinforced by the explicit age marking in pages created by younger grandparents. This second point is supported by N. Coupland et al. (1989), who might argue that age-marking is everywhere in these texts due to the ubiquitous marking of grandparent (age-related role) status. Thus, additional marking in terms of explicit disclosures of age is unnecessary. Finally, it may be that these grandparents are aware that marking age may not make for positive evaluations. Previous work has found that age-salient interactions may not be the most positive, be they within or outside of the family (Harwood et al., 2003; Williams \& Giles, 1996). Williams and Giles note that situations in which "age doesn't matter" are often those in which young people report the most positive intergenerational experiences. The grandparents in our data may be sufficiently attuned to such issues that they see 
age-marking as a likely turn-off to visitors to their sites. In other words, while the grandparenting relationship may be an interesting one in which to examine age identity as a social identity, it may be covertly rather than overtly communicated in some contexts. The data yield a few interesting indications for future research (e.g., in terms of the ways in which negative stereotypes of age and grandparenting are explicitly disassociated), however comments linking themes of age and grandparenting were sufficiently rare that further work and probably larger samples would be required to tease these out fully.

The most interesting finding in terms of the SIT background of this study was the pattern of grandparent role identification whereby it was often expressed in ways reminiscent of a social identification. Grandparents wrote about their role in ways that invoked a broader collective, and these comments were at times political in nature, emphasizing collective action or fighting for grandparents' rights. Such comments fall under the umbrella of social competition strategies as defined in the introduction-calls to collective action designed to challenge the status quo and achieve an improved social environment for one's group (Tajfel \& Turner, 1986). The impression from looking at the sites is that the intended audience for the more political sites is very different from the audience for the more "personal" sites (i.e., they appear to be tailored towards empowering other grandparents and perhaps challenging opponents). It is interesting to see such discourse with regard to an identity that would not be regarded as a social identity in the traditional sense of the term-as with a cultural group, for example. These findings suggest that future research might examine grandparenting identities in ways suggested by SIT (e.g., to what extent do grandparents dissociate from those who do not conform to good grandparenting practices-policing the boundaries of their group; in what ways do those who do not identify with the role deny it under certain conditions-social mobility). The findings suggest ways in which we might examine other collective identifications based on family role (e.g., a "father" identity), and specifically how those identifications are communicated in public and private settings.

A final connection to previous work is found in the apparently patronizing tone of certain pages. Grandchildren appeared to be addressed in "baby talk" on certain pages, and sections written by the grandparent from the grandchild's perspective also had a patronizing tone. This phenomenon was not sufficiently widespread to permit extensive analysis in the current data. However, this raises the issue of whether it is possible to observe intergenerational overaccommodation in Internet communication, and whether such overaccommodation has similar consequences to those observed in interpersonal settings. In particular, theories of intergenerational communication suggest that overaccommodation results in dissatisfaction and possibly serious health consequences (Hummert \& Ryan, 2001; Ryan, Giles, Bartolucci, \& Henwood, 1986). The Internet offers a new realm in which to examine such processes, particularly given the growing frequency of GP-GC communication using email (Fox et al., 2001).

\section{Limitations and Future Directions}

The sample from the web ring is clearly not a representative sample of all grandparents or all grandparenting-related web-sites. The grandparents involved are likely to be of relatively high socioeconomic status (they own and are comfortable with computers) and the pages are largely created for younger grandchildren (most younger than 15: This is inferred from the references to grandchild age and other evidence like photos). This suggests that these grandparents are themselves somewhat young relative 
to all grandparents. Older grandparents might have been more willing to mark their age in this kind of forum, given that taboos on age-disclosure in late middle-age appear to moderate in older adulthood (N. Coupland et al., 1989). In addition, we discovered in the process of the analysis that even the webring is not a reliable source of such sites, with almost $30 \%$ of the sites examined having no content relevant to grandparenting, even though they were linked to the ring. Presumably those sites' authors are grandparents who wanted to be linked to other grandparents, even though they were not inspired (for whatever reasons) to comment on their grandchildren on their web pages. Finally, as with much web research, we are stuck with trusting that the authors of these sites are who they claim to be-grandparents. It is possible that other individuals might actually have created these sites. This might not detract too much from a more general analysis of grandparent-related discourse, but independent verification of the author's exact status would have been useful. The authors' verification or perspective on the current analysis of the sites would also be useful: Such validation (while rare) strengthens the validity of qualitative research.

A number of interesting future research possibilities are apparent. First, work such as that reported here might be complemented by survey research. Some web pages include creators' contact information and it would be possible to send questionnaires. Such questionnaires might examine links between the websites' content and patterns of interpersonal communication in the relationship, as well as asking about the intended audiences for the sites. Second, additional methods of looking at the text of the site would provide triangulation of the findings. For instance, quantitative text analysis could potentially provide details on important conceptual relations in the text. Likewise, examination of other types of sites might allow for an understanding of the extent to which the dynamics uncovered here translate to different domains of identity. For instance, are similar themes apparent in sites for hobbyists (e.g., dog owners), people in intercultural or interracial relationships, twins, international adoptees, or alcoholics? As with the grandparent sites, the creators of such sites could be seen as having interesting relationships with persons or things and the potential for identifcation with others who share their interests or status. Such work would tell us more about how on-line discourse relates to relational and social identities.

\section{REFERENCES}

Annan, K. (1999). Address at the ceremony launching the international year of older persons. Journals of Gerontology, 5.4. P5-P6.

Baym, N. (1999). Tune in, log on: Soaps, fandom, and on-line community. Thousand Oaks, ( A: Sage.

Berger, C. R., \& Bradac, J. J. (1982). Language and social knowledge. London: Edward Amold.

Billig, M. (19!96). Arguing and thinking. Cambridge: Cambridge University Press.

Brussoni, M. J., \& Boon, S. D. IIMY8'. Grandparental impact in young adults' relationships with their closest grandparents: The role of relationship strength and emotional closeness. International Joumal of Aging and Human Development, 46, 267-286.

Burton, L. M., \& Bengtson, V. L. (198.5). Black grandmothers: Timing and continuity of roles. In V. 1 . Bengtson \& J. F. Robertson (Eds.) Grandparenthood (pp. (i1-78). Beverly Hills, CA: Sage.

Cai, D., Giles, H., \& Noels, K. (1998). Elderly perceptions of communication with older and younger adults in China: Implications for mental health. Joumal of Applied Communication Research, 26, 32-51.

Coupland, J., Coupland, N., Giles, H., \& Henwood, K. (1991). Finmulating age: Dimensions of age identity in elderly talk. Discourse Processes, 14, 87-106.

Coupland, J., Robinson, J., \& Coupland, N. (19!94). Frame negotiation in doctor-elderly patient consultations. Discourse and Society, 5,89-12.1.

Coupland, N., Coupland, J., \& Giles, H. 1 [!s!) . Telling age in later life. Text, 9, 129-151.

Duck, S. (19)?. Human relationships. Thousand Oaks, CA: Sage.

Fox, S., Rainie, L., Larsen, E., Horrigan, J., Ienhart, A., Spooner, T., \& Carter, C. (2001). Wired seniors: A fervent few inspired by family ties. Washington, DC: Pew Research Center. 
Garstka. T. A., Branscombe, N. R., \& Hummert, M. L. (2001). Age group identification in young, middle-aged, and older adults. Inpublished Manuscript, Gerontology Center, University of Kansas.

Gumperz, J., \& Levinson, S. (1996). Rethinking linguistic relativity. New York: Cambridge University Press.

Hajek, C., \& Giles, H. (2002). The old man out: An analysis of intergenerational communication among gay men. Journal of Communication, 52, 698-714.

Harwood, J. $(2(0)(0)$ ). Communication media use in the grandparent-grandchild relationship. Joumal of Communication, 50 (4), $56-78$.

Harwood, J. (2001). Comparing grandchildren's and grandparents' stake in their relationship. International Journal of Aging and Human Development, 53(3), 195-210.

Harwood,J., Giles, H., \& Ryan, E. B. (1995). Aging, communication, and intergroup theory: Social identity and intergenerational communication. In J. F. Nussbaum \& J. Coupland (Eds.), Handbook of communication and aging research (pp. 133-159). Hillsdale, NJ: Lawrence Erlbaum.

Harwood, J., Hewstone, M., Paolini, S., \& Voci, A. (2003). Intergroup contact theory, the grandparent-grandchild relationship, and altitudes towards older adults. Unpublished: University of Arizona.

Harwood, J., \& Lin, M-C. (2000). Affiliation, pride, exchange and distance in grandparents' accounts of relationships with their college-age grandchildren. Joumal of Communication, 50 (3), 31-47.

Harwood, J., McKee, J., \& Lin, M-C. (2000). Younger and older adults' schematic representations of intergenerational communication. Communication Monographs, 67, 20-41.

Hecht, M. L. (1993). 2002-a research odyssey: Toward the development of a communication theory of identity. Communication Monographs, 60, 76-82.

Holladay, S. J., \& Coombs, W. T. (2001, November). Media Portrayals of the Intergenerational Battle Over 'Grandparents' Rights': An Examination of the Troxell $v$ Granville Case. Paper presented at the annual meeting of the National Communication Association, Atlanta.

Holmes, D. (Ed.) (1997). Virtual politics: Identity and community in cyberspace. Thousand Oaks, CA: Sage.

Hummert, M. L., Garstka, T. A., Shaner, J. L.., \& Strahm, S. (1994). Stereotypes of the elderly held by young, middle-aged and elderly adults. Journal of Gerontology: Pychological Sciences, 49, 240-249.

Hummert, M. L., \& Ryan, E. B. (2001). Patronizing. In W. P. Robinson \& H. Giles (Eds.), The new handbook of language and social psychology (pp. 2:3-270). Chichester: John Wiley.

Kite. M. E., \& Johnson, B. T. (1988). Attitudes toward older and younger adults: A meta-analysis. Pycholog) and Aging, 3, 233-244.

Kornhaber, A. (1985). Grandparenthood and the "new social contract". In V. L. Bengtson \& J. F. Robertson (Eds.), Grandparenthood (pp. 159-172). Beverly Hills, CA: Sage.

Langellier, K. M., \& Peterson, E. E. (1993). Family storytelling as a strategy of social control. In D. Mumby (Ed.), Narrative and social control (pp. 49-76). Newbury Park, CA: Sage

Leets, L. (2001). Response to Internet hate sites: Is speech too free in cyberspace.' Communication Law and Policy, 6, 287-317.

Lin, M-C., Hummert, M. L., \& Harwood, J. (in press). Discursive representations of age identity in an on-line discussion group. Journal of Aging Studies.

Mavrogenes, N. A. (1982). Positive images of grandparents in children's picture books. Reading Teacher, 3.5, $896-901$.

Mitra, A. (1997). Virtual commonality: Looking for India on the Internet. In S. G. Jones (Ed.), Virtual cullure: Identity and communication in cyberspace (pp. 5.5-79). Thousand Oaks, CA: Sage.

$\mathrm{N}_{\mathrm{g}}, \mathrm{S}$. H., Lju, J. H., Weatherall, A., \& Loong, C. S. F. (1997). Younger adults' communication experiences and contact with elders and peers. Human Communication Research, 24, 82-108.

Nussbaum, J. F., \& Bettini, L. (19914). Shared stories of the grandparent-grandchild relationship. International Journal of Aging and Human Deoelopment, 39, 67-80.

Potter, J., \& Wetherell, M. (1!)87). Discourse and social psychology. London: Sage.

QSR (2000). N5 (Non-numerical Unstructured Data Indexing Searching \& Theorizing, Version 5.0). Melbourne, Australia: QSR International Pty Ltd..

Richards, Z., \& Hewstone, M. (2001). Subtyping and subgrouping: Processes for the prevention and promotion of stereotype change. Personality and Social Psychology Review, 5, 52-73.

Roberto, K. A., \& Stroes, J. (1992). Grandchildren and grandparents: Roles, influences, and relationships. International Joumal of Aging and Human Development, 34, 227-239.

Rowe, J. W., \& Kahn, R. L. (1998). Successful aging. New York: Random House.

Ryan, E. B., Giles, H., Bartolucci, G., \& Henwood, K. (1986). Psycholinguistic and social psychological components of communication by and with the elderly. Language and Communication, 6, 1-2.4

Ryan, E. B., Szechtman, B., \& Bodkin, J. (1992). Attitudes toward younger and older adults learning to use computers. Journal of Gerontology, 47, P96-101.

Seniornet (1998). Research on seniors' computer and Internet usage [Online, WWW page]. Available: http:// www.seniornet.org/research/rsch_(0998.html [2001, July 20th].

Silverman, D. (2001). Interpreting qualitalive data. Thousand Oaks, CA: Sage

Silverstein, M., \& Parrott, T. M. (1997). Attitudes toward public support of the elderly: Does early involvement with grandparents moderate generational tensions? Research on Aging, 19, $108-132$.

Soliz, J., \& Harwood, J. (2003). Communication in a close family relationship and the reduction of prejudic. Journal of Applied Communication Research, 31, 320-345. 
Strauss, A. L., \& Corbin, J. M. (1998). Basics of qualitative research; Techniques and procedures for developing grounded theory. Thousand Oaks, CA: Sage

Szinovacz, M. E. (Ed.) (1998). Handbook on grandparenthood. Westport, Connecticut: Greenwood Press.

Tajfel, H., \& Turner, J. C. (1986). The social identity theory of intergroup behavior. In S. Worschel and W. (;. Austin (eds.), The social psychology of intergroup relations (2nd ed.) (pp. 7-24). Chicago: Nelson.Hall.

Troxell vs. Granville, $99-138$ S. Ct. $(2(\%))$.

Turkle, S. (1995). Life on the screen: Identity in the age of the internet. New York: Simon \& Schuster.

Uhlenberg, P. (1996). Mortality decline in the twentieth century and supply of kin over the life course. The Gerontologist, 36, 681-685.

Williams, A. \& Giles, H. (1999(j). Intergenerational conversations: Young adult' retrospective accounts. Human Communication Research, 23, 220-250.

Wright, K. (2000). Computer-mediated social support, older adults, and coping. Joumal of Communication, 50 (3), 100-118.

White, H., McConnell, E., Clipp, R., Bynum, L., Teague, C., Navas, L., Craven, S., \& Halbrec ht, H. (1999). Surfing the net in later life: A review of the literature and pilot study of computer use and quality of life. Journal of Applied Gerontology, 18, 3.i. - 378 .

$W_{Y} n n, E ., \&$ Katz, J. E. (1997). Hyperbole over cyberspace: Self presentation and social boundaries in Internet home page's and discourse. The Information Society: An International Journal, 13(4), 2977-3328. 
Copyright of Communication Studies is the property of Central States Communication Association. The copyright in an individual article may be maintained by the author in certain cases. Content may not be copied or emailed to multiple sites or posted to a listserv without the copyright holder's express written permission. However, users may print, download, or email articles for individual use. 